\title{
Does the optimal position of the acetabular fragment should be within the radiological normal range for all developmental dysplasia of the hip? A patient-specific finite element analysis
}

Xuyi Wang ${ }^{1,2+}$, Jianping Peng ${ }^{2 \dagger}$, De $\mathrm{Li}^{2}$, Linlin Zhang ${ }^{3}$, Hui Wang ${ }^{2}$, Leisheng Jiang ${ }^{2^{*}}$ and Xiaodong Chen ${ }^{2^{*}}$

\begin{abstract}
Background: The success of Bernese periacetabular osteotomy depends significantly on how extent the acetabular fragment can be corrected to its optimal position. This study was undertaken to investigate whether correcting the acetabular fragment into the so-called radiological "normal" range is the best choice for all developmental dysplasia of the hip with different severities of dysplasia from the biomechanical view? If not, is there any correlation between the biomechanically optimal position of the acetabular fragment and the severity of dysplasia?

Methods: Four finite element models with different severities of dysplasia were developed. The virtual periacetabular osteotomy was performed with the acetabular fragment rotated anterolaterally to incremental center-edge angles; then, the contact area and pressure and von Mises stress in the cartilage were calculated at different correction angles.

Results: The optimal position of the acetabular fragment for patients 1,2, and 3 was when the acetabular fragment rotated $17^{\circ}$ laterally (with the lateral center-edge angle of $36^{\circ}$ and anterior center-edge angle of $58^{\circ}$; both were slightly larger than the "normal" range), $25^{\circ}$ laterally following further $5^{\circ}$ anterior rotation (with the lateral center-edge angle of $31^{\circ}$ and anterior center-edge angle of $51^{\circ}$; both were within the "normal" range), and $30^{\circ}$ laterally following further $10^{\circ}$ anterior rotation (with the lateral center-edge angle of $25^{\circ}$ and anterior center-edge angle of $40^{\circ}$; both were less than the "normal" range), respectively.

Conclusions: The optimal corrective position of the acetabular fragment is severity dependent rather than within the radiological "normal" range for developmental dysplasia of the hip. We prudently proposed that the optimal correction center-edge angle of mild, moderate, and severe developmental dysplasia of the hip is slightly larger than the "normal" range, within the "normal" range, and less than the lower limit of the "normal" range, respectively.
\end{abstract}

Keywords: Developmental dysplasia of the hip, Finite element analysis, Periacetabular osteotomy,

\footnotetext{
* Correspondence: 505516681@qq.com; chenxdmd@163.com

${ }^{\dagger}$ Equal contributors

${ }^{2}$ Department of Orthopaedics, Xinhua Hospital, Affiliated to Shanghai

Jiaotong University School of Medicine, Shanghai, China

Full list of author information is available at the end of the article
} 


\section{Background}

Bernese periacetabular osteotomy (PAO), as developed by Ganz et al. [1, 2], has been used for the treatment of developmental dysplasia of the hip (DDH) in adolescents and adults for more than 30 years. Good to excellent prognosis has been reported by many scholars [3-5]. Throughout the postoperative follow-up, however, we found that hip pain did not improve significantly and the cartilage degeneration continued to deteriorate for some DDH patients, even though their acetabular angle had been corrected into the "normal" range. The degree of correction for the acetabular fragment is not always directly proportional to the improvement of clinical symptoms, but this biomechanical mechanism has rarely been investigated.

At present, there are two main methods of biomechanical analysis: experimental biomechanics [6-9] and theoretical biomechanics [10, 11]. Experimental biomechanics is not widely used in the clinic due to the unavailability of cadaver specimens with acetabular dysplasia and the fact that the experiment cannot be repeated. Theoretical biomechanics is based on a mathematical model for numerical analysis, such as finite element analysis (FEA), which can handle different complex geometries and can provide various noninvasive mechanical tests [12-14]. However, FEA is a time-consuming, expensive, and professional task, impossible to perform in every DDH patients preoperatively under present social and economic conditions.

We therefore asked (1) whether the correction of the acetabular fragment into the so-called radiological "normal" range is the best choice for all DDH patients with different severities of dysplasia? (2) If not, is there any correlation between the biomechanically optimal position of the acetabular fragment and the severity of dysplasia in DDH patients? (3) Can we take advantage of this correlation and determine the optimal position of the acetabular fragment by measuring the morphological parameters of DDH without the help of FEA preoperatively?

Based on these questions, we selected three DDH patients (four hips) with different severities of dysplasia, performed virtual PAO on the FE model, and calculated the contact area and pressure, as well as von Mises stress in the articular cartilage as the acetabular fragment was corrected to different positions. Our aim was to find the optimal position of the acetabular fragment for DDH with differing dysplastic severities as well as the relationship between them and to offer valued help for surgeons formulating customized surgical planning.

\section{Methods}

All investigations were conducted in conformity with the Helsinki Declaration, and the study protocol was approved by our institutional review board (Ethics Committee of Xin Hua Hospital affiliated to Shanghai Jiao Tong University School of Medicine, Approval No. XHEC-D-2016-008).

Three dysplastic hips and one normal hip of three female patients with different severities of acetabular dysplasia were analyzed. To eliminate the effects of proximal femoral deformities on the numerical prediction, none of the patients were accompanied with hip varus or valgus, cam deformity of femoral head-neck junction. The clinical data for each patient are summarized in Table 1. A virtual PAO was performed with the acetabular fragment rotated anterolaterally to incremental center-edge (CE) angles, and the contact area and pressure and von Mises stress in the articular cartilage were calculated at different CE angles.

The severity of acetabular dysplasia of each subject was determined by measuring the acetabular angle and then comparing it with the value of normal hip preoperatively. Because the reliability and accuracy of the measurement based on conventional two-dimensional (2D) images (e.g., X-ray and 2D-CT) is susceptible to the positional variables, three-dimensional computerized tomography (3D-CT) reconstruction was used in this study. The lateral center-edge angle (LCEA) and the anterior center-edge angle (ACEA) of the normal hip are approximately $32^{\circ}$ and $54^{\circ}$, respectively, according to our previous research results [15], which is larger than the angles measured in 2D images (Fig. 1).

The 3D FE models of the femur and the pelvis were generated from preoperative CT scan data using the Abaqus 6.10-1 FE analysis software (Abaqus, Inc., Dassault Systemes Simulia Corp, Providence, RI) (Additional file 1: Figure S1, Additional file 2: Figure S2). Due to the various

Table 1 Clinical data of the three patients

\begin{tabular}{|c|c|c|c|c|c|c|c|c|}
\hline $\begin{array}{l}\text { Patient } \\
(\mathrm{NO})\end{array}$ & Gender & $\begin{array}{l}\text { Age } \\
\text { (years) }\end{array}$ & $\begin{array}{l}\text { BMI } \\
\left(\mathrm{kg} / \mathrm{m}^{2}\right)\end{array}$ & $\begin{array}{l}\text { LCEA } \\
\left({ }^{\circ}\right)\end{array}$ & $\begin{array}{l}\text { ACEA } \\
\left({ }^{\circ}\right)\end{array}$ & $\begin{array}{l}\text { Contact area } \\
\left(\mathrm{mm}^{2}\right)\end{array}$ & $\begin{array}{l}\text { Contact pressure } \\
(\mathrm{MPa})\end{array}$ & $\begin{array}{l}\text { von Mises stress } \\
(\mathrm{MPa})\end{array}$ \\
\hline 1 (left) & Female & 21 & 22 & 32 & 52 & 387.204 & 4.728 & 1.632 \\
\hline 1 (right) & Female & 21 & 22 & 19 & 47 & 327.067 & 5.759 & 2.169 \\
\hline 2 & Female & 28 & 20 & 7 & 22 & 276.247 & 6.328 & 2.393 \\
\hline 3 & Female & 29 & 24 & -7 & 11 & 225.634 & 6.935 & 2.514 \\
\hline
\end{tabular}

$B M I$ body mass index, $L C E A$ lateral center-edge angle, $A C E A$ anterior center-edge angle 


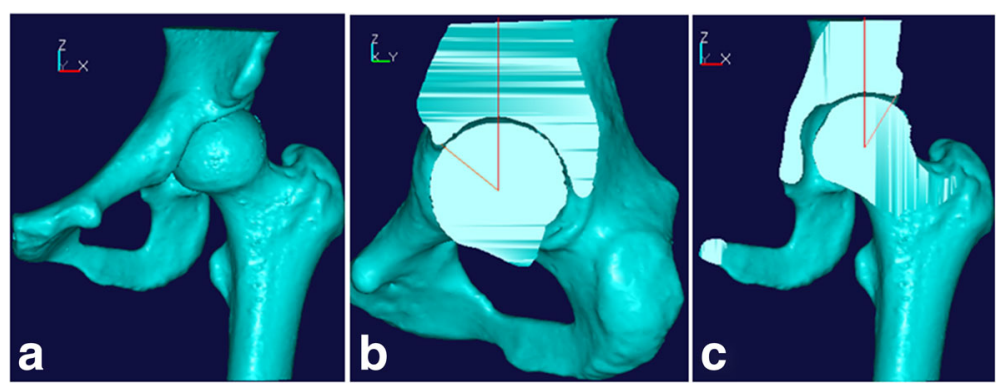

Fig. 1 The measurement methods of acetabular angle on 3D model. a The 3D reconstructed model using original CT data. b The sagittal image passing through the center of the femoral head; the intersection angle represents ACEA. $\mathbf{c}$ The coronal image passing through the center of the femoral head; the intersection angle represents LCEA

wearing degrees of articular cartilage and individual differences, the resultant cartilage layer varied in thickness from 1.5 to $2.0 \mathrm{~mm}$, corresponding to the joint clearance (Fig. 2a). Given the horseshoe shape of the acetabular cartilage, the region of the acetabular fossa was excluded (Fig. 2b). In vivo biomechanical experiments showed that the acetabular labrum and peripheral soft tissues also play important roles in the process of stress distribution in the hip joint $[16,17]$. We elongated the cartilage layer of acetabulum past the bone periphery of the acetabular rim by $2 \mathrm{~mm}$ [18], simulating the geometry of the labrum, and developed several spring elements connecting the pelvis and the proximal femur, simulating the peripheral soft tissues (Fig. 2c).

The bone and cartilage were meshed with ten node tetrahedral elements, which have four corners and sides. The number of elements and nodes were assigned using the method described by Zou et al. [19]. Different mesh densities (e.g., coarse, fine, and very fine) were used for each model to compare the average contact pressure and contact area in the articular cartilage. The optimal mesh size was chosen according to the criteria that a

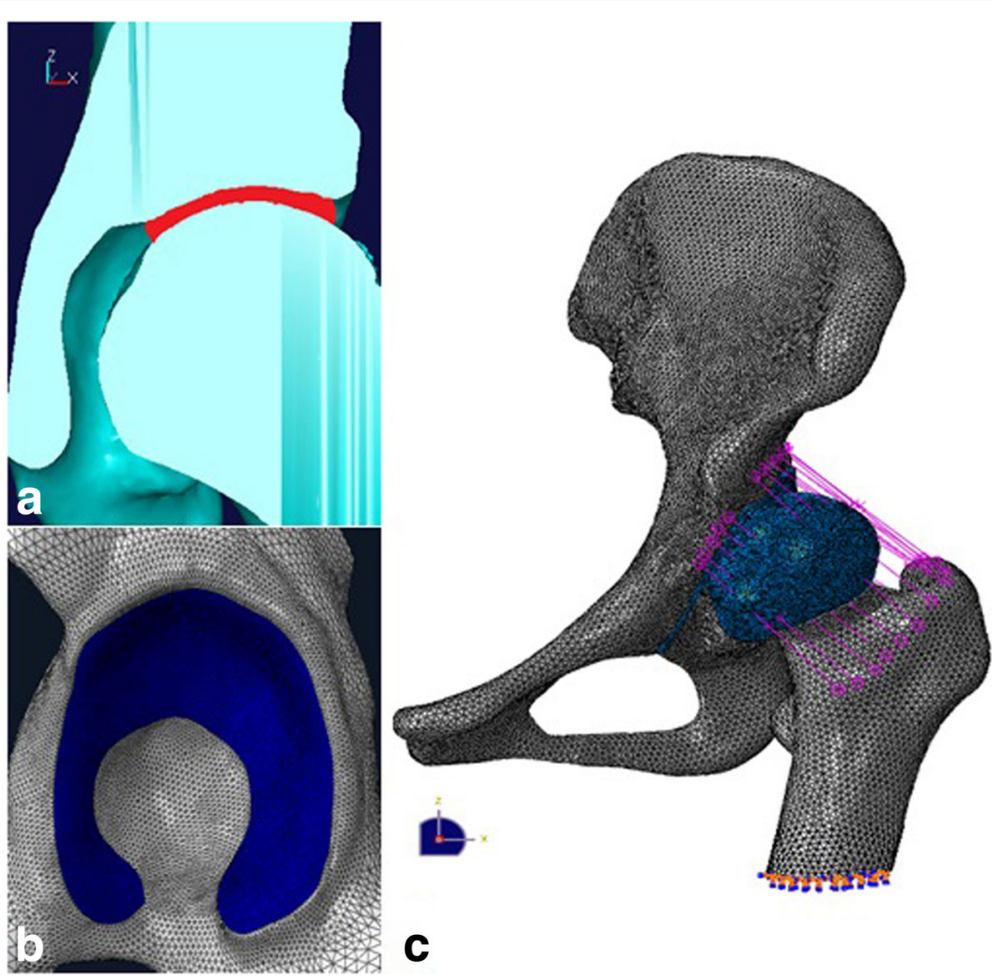

Fig. 2 The generation of articular cartilage and 3D FE model of the hip. a A red filling layer was constructed in the joint space between the femoral head and acetabulum; the bisected part of this layer was taken as acetabular cartilage and femoral head cartilage. b The constructed acetabular cartilage. c The constructed 3D FE model of the femur and pelvis, the blue layer represents the articular cartilage and the purple line represents the spring elements simulating the capsular ligaments 
change in the average contact pressure and contact area in the acetabular cartilage of $<1 \%$ between different meshes. Due to the different sizes and geometries, the optimal number of elements for each model was different. In this study, the average number of elements and nodes of cortical bone were 316,529 (244,380 to $408,547)$ and $92,043(69,848$ to 102,792$)$, respectively; in the trabecular bone, the average number of elements and nodes were $270,932(226,074$ to 303,851$)$ and 61,452 $(50,171$ to 71,934$)$; and the average number of elements and nodes in the cartilage were 421,439 (354,799 to $505,251)$ and $108,306(92,626$ to 122,078$)$.

The bony and articular cartilage of the model were assumed to be linear elastic and isotropic material with homogeneous properties. The biphasic and viscoelastic properties of cartilage were neglected because the loads involved in this study were of a noncyclic variation. Capsular ligaments consisted of several spring elements distributed around the hip joint along its anatomic location. The detailed parameters are listed in Table 2 $[20,21]$. The interface between the cartilage and bone was assumed completely bonded, and the cartilage surface between the acetabulum and femoral head was modeled as a frictionless sliding contact $[22,23]$.

The boundary and loading conditions used in this study were based on reports from the literature resembling the status with one leg stand $[19,24]$. All displacements and rotations of the distal parts of the femur were

Table 2 Element types and material properties

\begin{tabular}{|c|c|c|c|c|}
\hline Material & Element behavior & $\begin{array}{l}\text { Young's } \\
\text { modulus } \\
\text { E (MPa) }\end{array}$ & $\begin{array}{l}\text { Poisson's } \\
\text { ratio }\end{array}$ & $\begin{array}{l}\text { Stiffness } \\
\text { of spring } \\
(\mathrm{N} / \mathrm{mm})\end{array}$ \\
\hline Cortical bone & $\begin{array}{l}\text { Homogeneous, } \\
\text { linear elastic, } \\
\text { isotropic }\end{array}$ & 17,000 & 0.3 & - \\
\hline Trabecular bone & $\begin{array}{l}\text { Homogeneous, } \\
\text { linear elastic, } \\
\text { isotropic }\end{array}$ & 70 & 0.2 & - \\
\hline Articular cartilage & $\begin{array}{l}\text { Homogeneous, } \\
\text { linear elastic, } \\
\text { isotropic }\end{array}$ & 15 & 0.45 & - \\
\hline $\begin{array}{l}\text { Acetabular } \\
\text { labrum }\end{array}$ & $\begin{array}{l}\text { Homogeneous, } \\
\text { linear elastic, } \\
\text { isotropic }\end{array}$ & 15 & 0.45 & - \\
\hline Teres ligament & Spring element & - & - & $68 \pm 25$ \\
\hline $\begin{array}{l}\text { Ischiofemoral } \\
\text { ligament }\end{array}$ & Spring element & - & & $39.6 \pm 24.4$ \\
\hline $\begin{array}{l}\text { Pubofemoral } \\
\text { ligament }\end{array}$ & Spring element & - & - & $36.9 \pm 24.4$ \\
\hline $\begin{array}{l}\text { Inferior } \\
\text { iliofemoral } \\
\text { ligament }\end{array}$ & Spring element & - & - & $100.7 \pm 54$ \\
\hline $\begin{array}{l}\text { Superior } \\
\text { iliofemoral } \\
\text { ligament }\end{array}$ & Spring element & - & - & $97.8 \pm 67.5$ \\
\hline
\end{tabular}

fully constrained. The resultant hip joint force represented the abductor muscle force and five sixths of the body weight standing on one foot and the line of action of the applied force passing through the center of the head (Fig. 3a). The modeled load was applied to the reference point via kinematic coupling of Abaqus (Fig. 3b). The magnitude of the applied force was patient-specific and varied with the body weight of the subject (Fig. 3c).

According to Ganz's description [1], we performed virtual PAO on the 3D FE model. First, the acetabular fragment was rotated laterally around the center of femoral head until the LCEA closed to the "normal" range; then, the acetabular fragment was continuously rotated in $5^{\circ}$ increments up to the "normal" range. Following every $5^{\circ}$ of lateral rotation, the acetabular fragment was rotated anteriorly in $5^{\circ}$ increments. The contact area and pressure and von Mises stress in the articular cartilage were calculated at each acetabular angle.

\section{Results}

In this study, the original acetabular angle of patient 1's left hip exhibited an LCEA of $32^{\circ}$ and an ACEA of $52^{\circ}$, which were both within the "normal" range. And the patient had no complaints of discomfort about the left hip. We therefore regarded this hip as a normally developed hip. Following the above steps, the mechanical distribution in the acetabular cartilage of patient 1's left hip is shown in Fig. 4, the transmission of mechanics in the hip joint coincides with physiology. The contact area is wide, and the stress is dispersed in acetabular cartilage and is concentrated on the medial of the anterosuperior region, all of which are consistent with clinical observations. Furthermore, the FE model was validated indirectly by comparing the parameter predictions from this normal hip with the results obtained from cadaveric experiment [25]. In Bay's experiments, the mean age for the cadavers was 72 years (range of 42 to 86 years). To match his experimental conditions, the Young's modulus and Poisson's ratio used in the validated FE model were reduced to represent the typical reduction with age. Likewise, the loading and boundary conditions applied in the model validation corresponded to the conditions employed in cadaveric experiment. The contact area and pressure of the validated FE model were $387.204 \mathrm{~mm}^{2}$ and $4.728 \mathrm{MPa}$, respectively, which were lower than Bay's experimental contact area of $\sim 418 \mathrm{~mm}^{2}$ and pressure of $5.35 \mathrm{MPa}$. Nevertheless, the parameter predictions were comparable to Anderson's results, which ranged from 321.9 to $425.1 \mathrm{~mm}^{2}$ of contact area and 4.4 to $5.0 \mathrm{MPa}$ of contact pressure [26]. Racial diversity between the subjects may be the cause of these discrepancies; the subjects selected in this study were all young Asian females who have a smaller size and a lighter weight compared with the participants in other studies. 

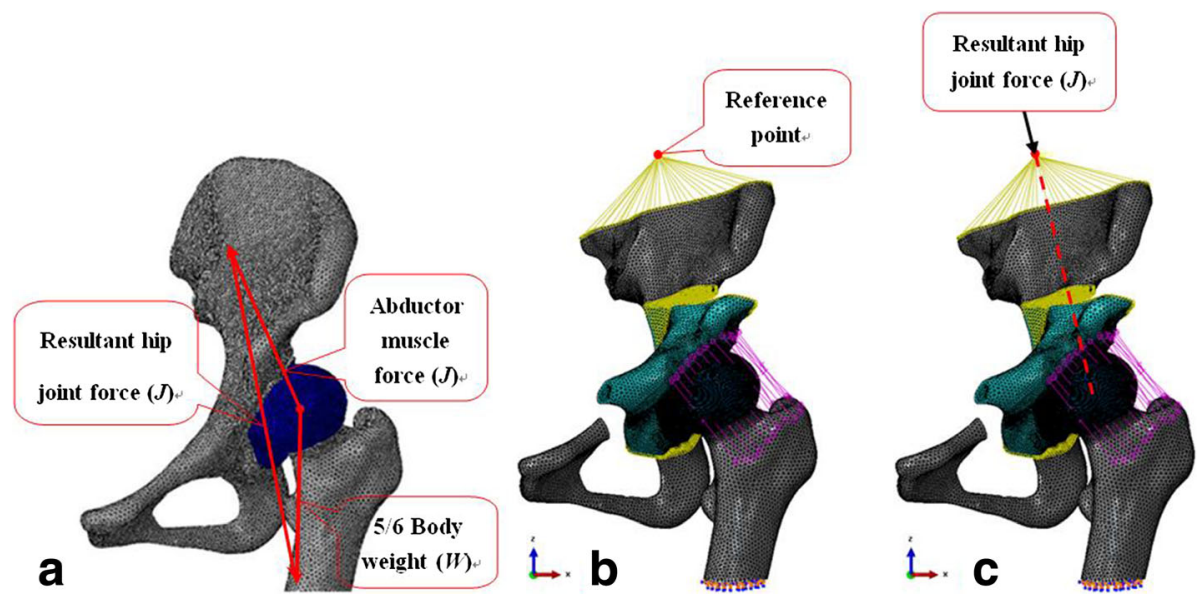

Fig. 3 Loading and boundary conditions of FE model. a The stress distribution in the hip joint standing one leg ( $\mathrm{J}$ resultant hip joint force; W 5/6 body weight; $F$ abductor muscle force $=1.6 \times W$ ). b Set reference point and build dynamic coupling device in Abaqus; The acetabular fragment and pelvis were bounded using the "tie" constraints of Abaqus. c The modeled load was applied to the reference point and the line of action of the applied force passing through the center of the head

On the whole, the trend of the parameter predictions changed to a single peak curve with the acetabular fragment had been rotated. Within a certain interval, the contact area gradually increased with the decrease of average contact pressure and von Mises stress during the rotation of acetabular fragment. However, after a critical point had been reached, the contact area did not significantly improve, and instead, the average contact pressure and von Mises stress would increase with the additional rotation of the fragment, even though the coverage of femoral head was increased (data shown in Additional file 3). This may be due to the subluxation of the hip, a mismatch between the curvatures of the acetabulum and the femoral head, which indicated that

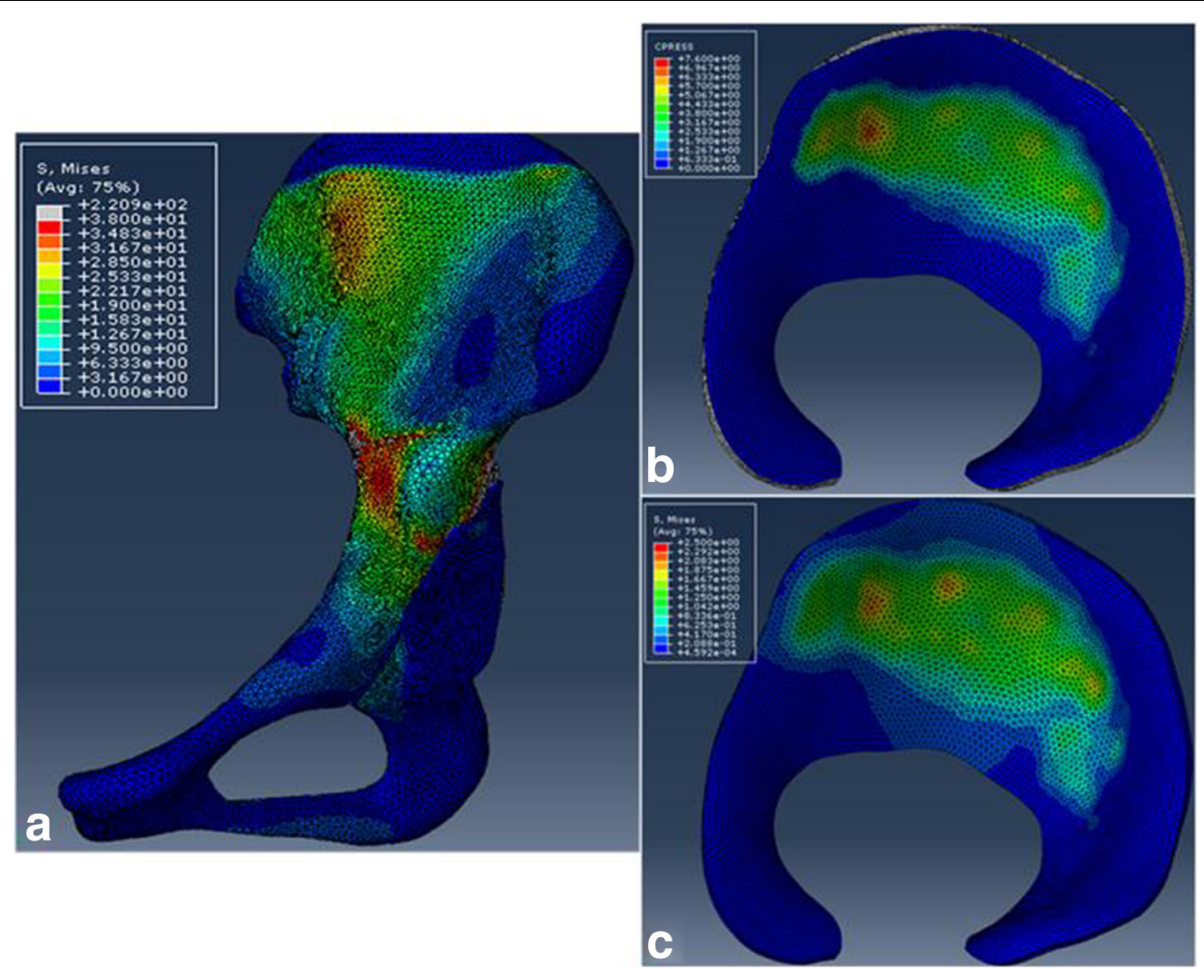

Fig. 4 The stress distribution cloud of patient 1's right hip. a The transmission of mechanics in the hip joint. b Contact pressure profile in acetabular cartilage. $\mathbf{c}$ von Mises stress profile in acetabular cartilage 
greater acetabular coverage does not necessarily mean a greater contact area between articular cartilage. Therefore, the actual contact area of the articular cartilage has a maximum critical value. When the hump of the curve was reached, the actual contact area between the articular cartilage would not increase further.

FE predictions also show that every patient has her own optimal correction of the acetabular fragment that maximizes contact area, while minimizing contact pressure and von Mises stress in the articular cartilage (Table 3). However, the optimal position of the acetabular fragment was not corrected with the acetabular angle into the so-called radiological "normal" range for all three DDH patients. Furthermore, the maximum contact area of patients 3 and 2 was lower than patient 1's left hip (the normal hip), while their acetabular fragment was corrected to the biomechanically optimal position. The minimum von Mises stress and contact pressure of patients 3 and 2 were bigger than patient 1's left hip (data shown in Additional file 3).

The contact pressure profile in acetabular cartilage further confirmed that the contact area and pressure improved gradually as the acetabular fragment was corrected anterolaterally within a definite scope. However, the contact area did not improve significantly and even decreased sometimes, and the contact pressure rose gradually when the fragment was furtherly rotated outside of the scope. Figure 5 shows how the contact area and pressure changed in the acetabular cartilage as the acetabular fragment rotated anterolaterally in patient 3. As shown in the contact pressure profile in acetabular cartilage, the stress distribution in acetabular cartilage dispersed, and the peak contact pressure decreased; meanwhile, the stress concentration shifted from the edge of the superolateral region toward the medial of the superior region as the acetabular angle was corrected. The optimal position was reached when the acetabular fragment was rotated $30^{\circ}$ laterally following a further $10^{\circ}$ anterior rotation.

\section{Discussion}

Because of its advantages such as the maintenance of an intact dorsal pillar without compromising the dimensions of the birth canal and allowing acetabulum

Table 3 Correction degree of the acetabular fragment to achieve the optimal position

\begin{tabular}{lllll}
\hline & $\begin{array}{l}\text { Lateral } \\
\text { rotation } \\
\left({ }^{\circ}\right)\end{array}$ & $\begin{array}{l}\text { Anterior } \\
\text { rotation } \\
\left({ }^{\circ}\right)\end{array}$ & $\begin{array}{l}\text { Final } \\
\text { LCEA } \\
\left({ }^{\circ}\right)\end{array}$ & $\begin{array}{l}\text { Final } \\
\text { ACEA } \\
\left({ }^{\circ}\right)\end{array}$ \\
\hline Patient 1 (right hip) & 17 & 0 & 36 & 58 \\
Patient 2 & 25 & 5 & 31 & 51 \\
Patient 3 & 30 & 10 & 25 & 40 \\
\hline
\end{tabular}

LCEA Lateral center-edge angle, ACEA Anterior center-edge angle reorientation in any directions [1], PAO has become the preferred choice as hip-preserving surgery for treating DDH patients. The critical and difficult part of the procedure is to confirm the optimal position of the acetabular fragment. There are many studies about FEA of PAO in DDH hips [19, 21, 27, 28]. However, the correlation between the optimal position and the severity of dysplasia was seldom investigated in these studies.

In this study, we performed FEA of PAO for three $\mathrm{DDH}$ patients with different severities of dysplasia, and we confirmed that the optimal position of the acetabular fragment is severity dependent and was not always corrected to the so-called radiological "normal" range. For example, patient 3 exhibited severe acetabular dysplasia with an original LCEA of $-7^{\circ}$ and an ACEA of $11^{\circ}$. The optimal position was when the fragment was rotated $30^{\circ}$ laterally following further $10^{\circ}$ anterior rotation, where the final LCEA of $25^{\circ}$ and ACEA of $40^{\circ}$ were both lower than the "normal" range. Patient 2 was a moderate acetabular dysplasia with an original LCEA of $7^{\circ}$ and an ACEA of $22^{\circ}$, the optimal position was when the fragment was rotated $25^{\circ}$ laterally following further $5^{\circ}$ anterior rotation, where the final LCEA of $31^{\circ}$ and ACEA of $51^{\circ}$ were both within the "normal" range. Patient 1's right hip exhibited a mild acetabular dysplasia with an original LCEA of $19^{\circ}$ and an ACEA of $47^{\circ}$, the optimal position was when the fragment rotated $17^{\circ}$ laterally, where the final LCEA of $36^{\circ}$ and ACEA of $58^{\circ}$ were slightly larger than the "normal" range.

The causes of these findings were analyzed. First, because of a serious deficiency of periacetabular bone stock for severe acetabular dysplasia coupled with the wavy morphology of acetabular rim, if we struggling to restore the acetabular angle within the so-called "normal" range for this severe dysplastic hip, a large rotation of the osteotomized fragment would be needed, therefore, the tension in soft tissue around the hip joint would increase accordingly, while the actual contact area of the articular cartilage would not increase significantly. Second, the one dimensional coverage deficiency was corrected, which could compromise the other dimensional coverage in three-dimensional space [29-31]. That is, the anterolateral coverage deficiency was corrected as the acetabular fragment was rotated, the posterior coverage deficiency was simultaneously aggravated, which would lead to hip joint instability. Third, femoroacetabular impingement maybe another adverse impact of a large rotation of the osteotomized fragment in three-dimensional space, which would shorten the distance between the acetabulum and the proximal femur. Ziebarth et al. [32] reported a high rate of femoroacetabular impingement after PAO, despite restoring the normal acetabular coverage. All of these causes will lead to disequilibrated mechanical transmission into the 


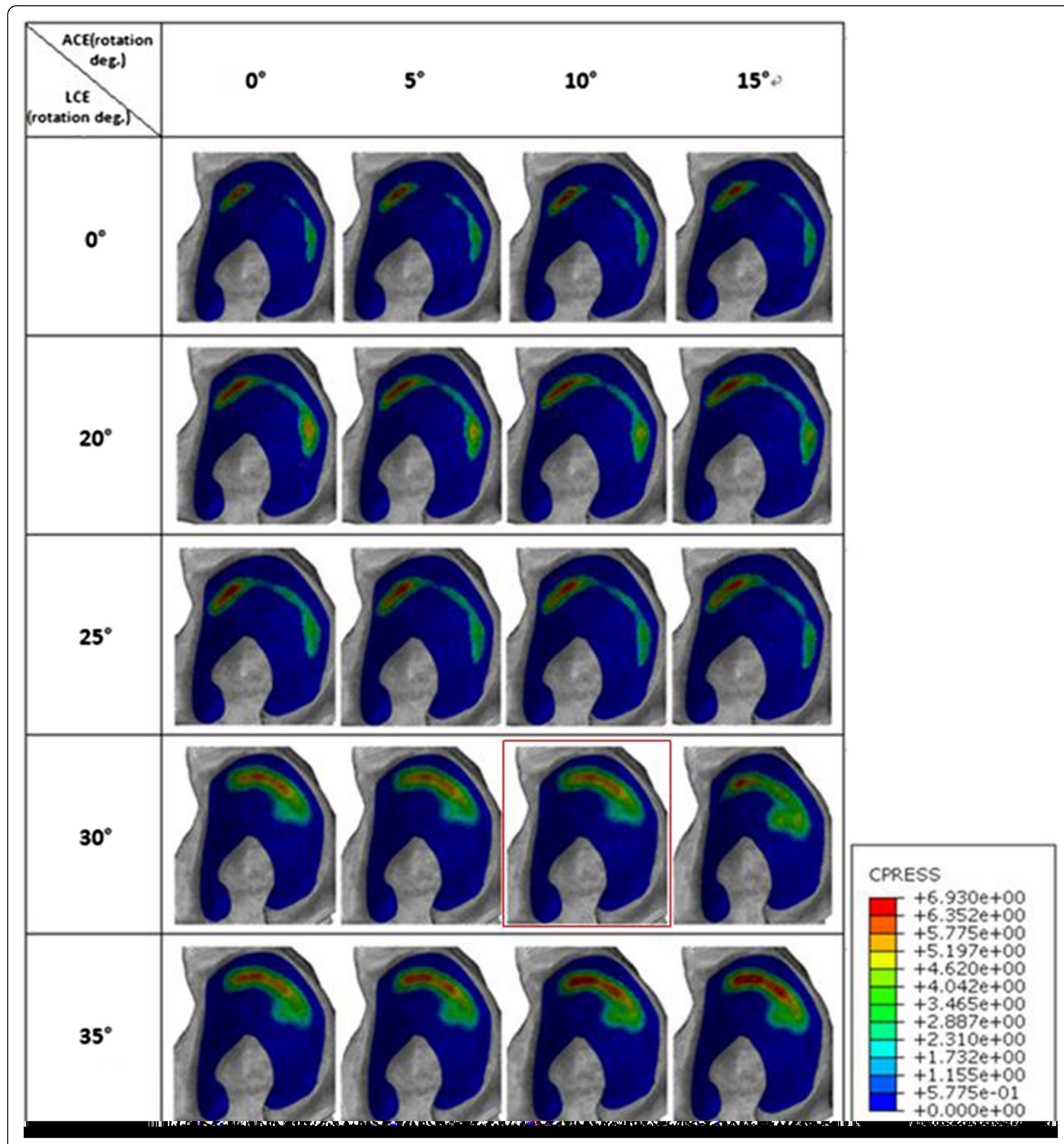

Fig. 5 Contact pressure profile in acetabular cartilage of patient 3 at different CE angles. The red box means the optimal correction angle of patient 3, where the contact area was maximized and contact pressure and von Mises stress were minimized

hip joint and finally cause the average contact pressure and von Mises stress increase in the articular cartilage. For mild and moderate DDH patients, due to the better development and congruence of the hip, the geometrical morphology was not altered significantly when the acetabulum was corrected to a slightly larger acetabular angle, and because of the increase of the acetabular coverage, the biomechanical environment of the hip can obtain the maximum level of improvement.

DDH is a complex musculoskeletal malformation, and PAO surgery can improve the contact area between acetabular cartilage and rebuild the near-normal biomechanical environment of the hip through the correction of the acetabular fragment, however, it cannot recover the 
normal anatomic structure of the hip. The parameter predictions of severe and moderate DDH (such as patients 2 and 3) are worse than those of normal hips. This may be the mechanical reason for poor prognosis of PAO for these severe and moderate DDH patients.

Finite element results also show that the contact area, average contact stress and von Mises stress did not significantly improve and even worsened when the acetabular fragment was rotated laterally following additional anterior rotation. Since the anterior coverage of the acetabulum increased simultaneously when the acetabular fragment was rotated laterally in three-dimensional space, a great anterior rotation would increase the risk of femoroacetabular impingement. Surgeons should therefore be careful with the anterior rotation of the acetabular fragment when performing PAO, especially for those DDH patients whose anterior coverage deficiency was not serious (such as patients 2 and 3).

This study has several limitations. First, as a numerical simulation investigation, FEA has its inherent limitations such as simplified treatment in the material properties and loading and boundary conditions, which may have some impact on the analytic results. Using similar experimental conditions, the numerical predictions were successfully corroborated against the results from a cadaveric experiment [25], which validated the FE model for this study. Second, only the loading condition of a single-legged stance was investigated in this study. Therefore, the effect of PAO on stress distribution in articular cartilage in loading conditions of other daily activities and other phase of the entire gait cycle could not be evaluated, and this is the focus of our future research. Third, only three subjects were studied; the sample size in this study was relatively small. Further investigations would include more subjects with different severities of dysplasia. Fourth, we did not consider the proximal femoral deformities in the analysis in this study. It is true that not only the correction of acetabular fragment but also the proximal femur influences the mechanical transmission in the hip joint. However, there are only a few DDH patients accompanied by proximal femoral deformities, especially for those mild and moderate DDH. Therefore, we focused on the effect of different severities of acetabular dysplasia on mechanical transmission in the hip joint in this study.

\section{Conclusions}

In summary, our FE models demonstrate the clinical hypothesis from the view of mechanics that the optimal corrective position of the acetabular fragment is severity dependent rather than within the radiological "normal" range for all DDH patients. We prudently propose that the optimal correction $\mathrm{CE}$ angle of mild, moderate, and severe DDH is slightly larger than the "normal" range, within the "normal" range, and less than the lower limit of the "normal" range, respectively, and hope that this information could help orthopedic surgeons in customized surgical planning.

\section{Additional files} Additional file 1: Figure S1. The STL model of the hip generated by
Mimics 10.01. (TIF $1 \mathrm{MB}$ )

Additional file 2: Figure S2. The $3 D$ surface model of the hip generated by Geomagic 12.0. (TIF $1 \mathrm{MB}$ )

Additional file 3: Supplementary table. The contact area, verage contact pressure and Von Mises stress in the acetabular cartilage of patient 1's right hip, patient 2 and patient 3 at different CE angles. (DOCX $19 \mathrm{~kb}$ )

\section{Abbreviations}

ACEA: Anterior center-edge angle; DDH: Developmental dysplasia of the hip; FEA: Finite element analysis; LCEA: Lateral center-edge angle; PAO: Bernese periacetabular osteotomy

\section{Acknowledgements}

The study was financially supported by the National Natural Science Foundation of China (No. 81171705) and the National Natural Science Foundation of Youth in China (No. 81101381), Shanghai Municipal Commission of Health and Family Planning Foundation (No. 20134002), and Research Foundation of Shanghai Jiaotong University Medical School (No. 14XJ10031).

\section{Funding}

Not applicable.

\section{Availability of data and materials}

All relevant raw data for this study have been presented in the main manuscript or additional supporting files, which are freely available to any scientist wishing to use them, without breaching participant confidentiality.

\section{Authors' contributions}

XYW and JPP participated in the design of the study, manuscript preparation, data statistical analysis, and revision. LLZ is responsible for the FE model creation and calculation of the data. DL and HW advised and assisted in the drafting of the manuscript. CS and JFZ participated in revising critically the manuscript. LSJ is responsible for the revision of the manuscript and financial support to the experiment. XDC is responsible for the study design, financial support, and general supervision of the research group. All authors read and approved the final manuscript.

\section{Competing interests}

The authors declare that they have no competing interests.

\section{Consent for publication}

Consent for publication was obtained from all patients.

\section{Ethics approval and consent to participate}

All investigations were conducted in conformity with the Helsinki Declaration, and the study protocol was approved by our institutional review board (Ethics Committee of Xin Hua Hospital affiliated to Shanghai Jiao Tong University School of Medicine, Approval No. XHEC-D-2016-008). All patients received a thorough explanation of this study and gave their oral and written informed consent to be included in this analysis.

\section{Author details}

'Department of Orthopaedics, The First Affiliated Hospital of Bengbu Medical College, Bengbu, Anhui, China. ${ }^{2}$ Department of Orthopaedics, Xinhua Hospital, Affiliated to Shanghai Jiaotong University School of Medicine, Shanghai, China. ${ }^{3}$ Department of Biomedical Engineering, Shanghai University of Technology, Shanghai, China. 
Received: 14 March 2016 Accepted: 27 September 2016

Published online: 04 October 2016

\section{References}

1. Ganz R, Klaue K, Vinh TS, Mast JW. A new periacetabular osteotomy for the treatment of hip dysplasias. Technique and preliminary results. Clin Orthop Relat Res. 1988:232:26-36.

2. Siebenrock KA, Scholl E, Lottenbach M, Ganz R. Bernese periacetabular osteotomy. Clin Orthop Relat Res. 1999;363:9-20.

3. Garras DN, Crowder TT, Olson SA. Medium-term results of the Bernese periacetabular osteotomy in the treatment of symptomatic developmenta dysplasia of the hip. J Bone Joint Surg. 2007;89(6):721-4.

4. Siebenrock KA, Schaller C, Tannast M, Keel M, Buchler L. Anteverting periacetabular osteotomy for symptomatic acetabular retroversion: results at ten years. J Bone Joint Surg Am. 2014:96(21):1785-92.

5. Steppacher SD, Tannast M, Ganz R, Siebenrock KA. Mean 20-year followup of Bernese periacetabular osteotomy. Clin Orthop Relat Res. 2008;466(7):1633-44.

6. D'Lima DD, Fregly BJ, Colwell Jr CW. Implantable sensor technology: measuring bone and joint biomechanics of daily life in vivo. Arthritis Res Ther. 2013:15(1):203

7. Pfeifer $\mathrm{R}$, Hurschler $\mathrm{C}$, Ostermeier $\mathrm{S}$, Windhagen $\mathrm{H}$, Pressel $\mathrm{T}$. In vitro investigation of biomechanical changes of the hip after Salter pelvic osteotomy. Clin Biomech. 2008;23(3):299-304.

8. Schwachmeyer V, Damm P, Bender A, Dymke J, Graichen F, Bergmann G. In vivo hip joint loading during post-operative physiotherapeutic exercises. PLoS One. 2013:8(10):e77807.

9. von Eisenhart R, Adam C, Steinlechner M, Muller-Gerbl M, Eckstein F. Quantitative determination of joint incongruity and pressure distribution during simulated gait and cartilage thickness in the human hip joint. J Orthop Res. 1999;17(4):532-9.

10. Farrokhi S, Keyak JH, Powers CM. Individuals with patellofemoral pain exhibit greater patellofemoral joint stress: a finite element analysis study. Osteoarthritis Cartilage. 2011;19(3):287-94.

11. Gao $Y$, Jin Z, Wang L, Wang M. Finite element analysis of sliding distance and contact mechanics of hip implant under dynamic walking conditions. Proc Inst Mech Eng H. 2015;229(6):469-74.

12. Er MS, Eroglu M, Verim O, Altinel L. Finite element analysis of the pelvis after modular hemipelvic endoprosthesis reconstruction. Int Orthop. 2013;37(10):2097-8.

13. Henak CR, Ellis BJ, Harris MD, Anderson AE, Peters CL, Weiss JA. Role of the acetabular labrum in load support across the hip joint. J Biomech. 2011;44(12):2201-6.

14. Viceconti M, Olsen S, Nolte LP, Burton K. Extracting clinically relevant data from finite element simulations. Clin Biomech (Bristol, Avon). 2005;20(5):451-4.

15. Xuyi W, Jianping $P$, Junfeng Z, Chao S, Yimin C, Xiaodong C. Application of three-dimensional computerised tomography reconstruction and image processing technology in individual operation design of developmental dysplasia of the hip patients. Int Orthop. 2015;40(2):255-65.

16. Henak CR, Carruth ED, Anderson AE, Harris MD, Ellis BJ, Peters CL, Weiss JA. Finite element predictions of cartilage contact mechanics in hips with retroverted acetabula. Osteoarthritis Cartilage. 2013;21(10):1522-9.

17. Ghosh R, Pal B, Ghosh D, Gupta S. Finite element analysis of a hemi-pelvis: the effect of inclusion of cartilage layer on acetabular stresses and strain. Comput Methods Biomech Biomed Engin. 2015;18(7):697-710.

18. Won YY, Chung $H_{\text {, }}$ Chung NS, Song KH. Morphological study on the acetabular labrum. Yonsei Med J. 2003:44(5):855-62.

19. Zou Z, Chavez-Arreola A, Mandal P, Board TN, Alonso-Rasgado T. Optimization of the position of the acetabulum in a Ganz periacetabular osteotomy by finite element analysis. J Orthop Res. 2013;31(3):472-9.

20. Alonso-Rasgado T, Jimenez-Cruz D, Bailey CG, Mandal P, Board T. Changes in the stress in the femoral head neck junction after osteochondroplasty for hip impingement: a finite element study. J Orthop Res. 2012;30(12):1999-2006.

21. Zhao X, Chosa E, Totoribe K, Deng G. Effect of periacetabular osteotomy for acetabular dysplasia clarified by three-dimensional finite element analysis. J Orthop Res. 2010;15(5):632-40.

22. Ike H, Inaba Y, Kobayashi N, Yukizawa Y, Hirata Y, Tomioka M, Saito T. Effects of rotational acetabular osteotomy on the mechanical stress within the hip joint in patients with developmental dysplasia of the hip: a subject-specific finite element analysis. Bone Joint J. 2015:97-B(4):492-7.

23. Chegini S, Beck M, Ferguson SJ. The effects of impingement and dysplasia on stress distributions in the hip joint during sitting and walking: a finite element analysis. J Orthop Res. 2009;27(2):195-201.
24. Grecu D, Pucalev I, Negru M, Tarnita DN, Ionovici N, Dita R. Numerical simulations of the 3D virtual model of the human hip joint, using finite element method. Rom J Morphol Embryol. 2010;51(1):151-5.

25. Bay BK, Hamel AJ, Olson SA, Sharkey NA. Statically equivalent load and support conditions produce different hip joint contact pressures and periacetabular strains. J Biomech. 1997;30(2):193-6.

26. Anderson $A E$, Ellis $B J$, Maas $S A$, Peters $C L$, Weiss JA. Validation of finite element predictions of cartilage contact pressure in the human hip joint. J Biomech Eng. 2008;130(5):051008.

27. Mavcic B, Pompe B, Antolic V, Daniel M, Iglic A, Kralj-Iglic V. Mathematical estimation of stress distribution in normal and dysplastic human hips. J Orthop Res. 2002;20(5):1025-30.

28. Tsumura H, Kaku N, Ikeda S, Torisu T. A computer simulation of rotational acetabular osteotomy for dysplastic hip joint: does the optimal transposition of the acetabular fragment exist? J Orthop Res. 2005;10(2):145-51.

29. Fujii M, Nakashima Y, Sato T, Akiyama M, Iwamoto Y. Acetabular tilt correlates with acetabular version and coverage in hip dysplasia. Clin Orthop Relat Res. 2012;470(10):2827-35.

30. Kohnlein W, Ganz R, Impellizzeri FM, Leunig M. Acetabular morphology: implications for joint-preserving surgery. Clin Orthop Relat Res. 2009;467(3):682-91.

31. Vandenbussche E, Saffarini M, Taillieu F, Mutschler C. The asymmetric profile of the acetabulum. Clin Orthop Relat Res. 2008:466(2):417-23.

32. Ziebarth K, Balakumar J, Domayer S, Kim YJ, Millis MB. Bernese periacetabular osteotomy in males: is there an increased risk of femoroacetabular impingement (FAl) after Bernese periacetabular osteotomy? Clin Orthop Relat Res. 2011:469(2):447-53.

\section{Submit your next manuscript to BioMed Central and we will help you at every step:}

- We accept pre-submission inquiries

- Our selector tool helps you to find the most relevant journal

- We provide round the clock customer support

- Convenient online submission

- Thorough peer review

- Inclusion in PubMed and all major indexing services

- Maximum visibility for your research

Submit your manuscript at www.biomedcentral.com/submit
Biomed Central 